\title{
An Exploration of Problematic Smartphone Use among Chinese University Students: Associations with Academic Anxiety, Academic Procrastination, Self-Regulation and Subjective Wellbeing
}

\author{
Zeyang Yang ${ }^{1}$ (D) Kathryn Asbury ${ }^{1} \cdot$ Mark D. Griffiths $^{2}$
}

Published online: 9 July 2018

(C) The Author(s) 2018

\begin{abstract}
Over the past decade, there have been an increasing number of studies that have investigated problematic and/or 'addictive' smartphone use. The present study explored the prevalence and correlates of problematic smartphone use (PSU) among Chinese university students. Few studies have investigated relationships between PSU and factors such as academic anxiety, academic procrastination, self-regulation, and subjective wellbeing. The present study proposed and tested a hypothetical model of relationships between PSU and these factors. A total of 475 Chinese university students completed a paper-based survey during class breaks. The survey comprised a battery of psychometric scales translated into Chinese translations examining the study variables (i.e., academic anxiety, academic procrastination, self-regulation, life satisfaction, and PSU). Path analysis was applied to test the hypothetical model. A good model fit was found $(\mathrm{CFI}=1.00, \mathrm{RMSEA}=0.008)$, in which PSU predicted academic procrastination $(\beta=0.21, p<0.001)$ and academic anxiety $(\beta=0.18$, $p<0.01)$. Also, self-regulation predicted PSU $(\beta=-0.35, p<0.001)$, academic anxiety $(\beta=-$ $0.29, p<0.001)$, academic procrastination $(\beta=0.23, p<0.001)$ and life satisfaction $(\beta=0.23$, $p<0.001)$. PSU mediated the relationships between self-regulation, and both academic anxiety and academic procrastination. The present study enhances our understanding of the role of problematic smartphone use in relation to academic behaviour, mental health and wellbeing of college students.
\end{abstract}

Keywords Problematic smartphone use - Smartphone addiction · Academic anxiety · Academic procrastination $\cdot$ Self-regulation $\cdot$ Life satisfaction

Zeyang Yang

zy664@york.ac.uk; yangzeyangyzy@hotmail.com

1 Psychology in Education Research Centre, Department of Education, University of York, York YO10 5DD, UK

2 International Gaming Research Unit, Psychology Department, Nottingham Trent University, Nottingham, UK 
In 2016, $62.9 \%$ of people around the world owned a mobile phone, and the number is predicted to reach $67 \%$ by 2019 (Statista n.d.). In China, mobile phone ownership is much higher than the global average. The number of mobile phone users in China reached 1.42 billion in November 2017, although this figure includes all mobile phones and not just smartphones which are the focus of the current investigation (Ministry of Industry and Information Technology of the People's Republic of China 2018). The prevalence of smartphone ownership in China was 58\% in 2015 (Poushter 2016). Although mobile phones, especially smartphones, offer benefits in terms of communication and access to information, there is growing evidence that they can have negative effects and that their use can become problematic among a small minority of individuals (e.g. Bianchi and Phillips 2005; Billieux et al. 2015a; Carbonell et al. 2012; Hussain et al. 2017; Lopez-Fernandez et al. 2017). Several symptoms of problematic smartphone use have been identified including excessive reassurance behaviours (e.g. constantly checking for new messages) and use in inappropriate situations such as using smartphones while driving (Billieux et al. 2015a).

Furthermore, evidence suggests that problematic smartphone use may be a particular problem in China. For instance, Long et al. (2016) found that the prevalence of problematic smartphone use among undergraduates $(n=1062)$ in Mainland China $(21.3 \%)$ was higher than in similar samples in other Asian regions such as South Korea (11.4\%) and Taiwan (16.4 to 16.7\%). All of these studies used the same instrument (Problematic Cellular Phone Use Questionnaire, PCPUQ, Yen et al. 2009) and the same diagnostic criteria. Explanations for this observed difference remain unclear. Also, several recent Chinese studies have found college students' smartphone use to be associated with poor psychological wellbeing, anxiety and loneliness (Bian and Leung 2015; Huang et al. 2013; Long et al. 2016). Thus, it appears important to investigate whether problematic smartphone use is particularly prevalent among Chinese college students and whether it is associated with negative psychological outcomes for them. The present study was designed primarily to explore relationships between problematic smartphone use and potential correlates that are relevant to student life, such as academic anxiety, academic procrastination, self-regulation and life satisfaction.

\section{Problematic Smartphone Use}

Ever since Griffiths (1995) published his paper on 'technological addictions, many authors have labelled problematic mobile phone or Internet use as an addiction, using terms such as 'mobile phone addiction', 'smartphone addiction', and 'Internet addiction' (e.g. Griffiths 2000; Hong et al. 2012; Liu and Kuo 2007; Widyanto and Griffiths 2006; Young 1998a, b). Such terminology draws on the idea of 'technological addiction' referring to 'nonchemical (behavioural) addictions which involve human-machine interaction' (Griffiths 1995, p. 15). However, it is important to note that there are no diagnostic criteria for mobile phone addiction in the most recent (fifth) edition of the Diagnostic and Statistical Manual of Mental Disorders (DSM-5; American Psychiatric Association (2013), although one form of Internet use disorder (i.e. Internet gaming disorder) appears in Sect. 3 as an emerging disorder and is conceptualised as a behavioural addiction similar to gambling disorder (American Psychiatric Association 2013). Consequently, most of the studies in this area have relied on diagnostic criteria for substance dependence and/or pathological gambling (Kuss et al. 2014). Billieux et al. (2015b) have argued against this practice, making the case that it is overly simplistic to judge overuse, or problematic use, of mobile phones as an addiction, although Griffiths $(2005,2017)$ has 
argued that any behaviour that comprises all of the core characteristics of addiction (e.g. salience, conflict, tolerance, relapse, mood modification and withdrawal symptoms) should be defined as such.

Billieux et al. (2015a) proposed a theoretical pathway model which represents the complexity of problematic mobile phone use, including addiction-like symptoms, and emphasises psychological factors including anxiety symptoms and self-control. The present study takes a similar approach to this and focuses on psychological correlates of problematic smartphone use. Because of the high rate of smartphone possession among Chinese undergraduates $(99.2 \%$ reported by Long et al. (2016)), the present study focuses on smartphone use (i.e. Wi-Fi enabled mobile phones) rather than mobile phone use and will use the term 'problematic smartphone use' (PSU).

\section{Academic Anxiety and PSU}

Many empirical studies have found that anxiety is associated with increased smartphone use including dependence and so-called smartphone addiction (e.g. Akin and Iskender 2011; Ha et al. 2008; Hong et al. 2012; Jenaro et al. 2007; Lepp et al. 2014; Leung 2008; Wang et al. 2014; Yang and Lay 2011; Zboralski et al. 2009). Studies of Chinese college students have also found anxiety to be associated with PSU (Huang et al. 2013; Long et al. 2016)). Furthermore, theoretical approaches have also suggested an association between anxiety and PSU (Billieux 2012; Billieux et al. 2015a) and pathological Internet use (Davis 2001). The trait-state anxiety theory (Spielberger 1972) indicates that anxiety-inducing situations, perceived by an individual as threatening, may evoke behavioural reactions, which could potentially include certain types of smartphone use. Such reactions may be used as coping mechanisms in order to reduce the intensity of the anxiety felt in the face of a perceived threat.

However, empirical studies of the relationship between PSU and anxiety have yielded mixed findings, particularly relating to the direction of effects. For example, one study reported that higher frequency of mobile phone use predicted higher levels of anxiety, albeit with a limited effect size (Lepp et al. 2014). However, in an earlier study, higher levels of anxiety were found to predict higher levels of self-reported mobile phone use (Jenaro et al. 2007). This lack of clarity regarding direction of effects is perhaps unavoidable in correlational research. Further complicating the issue, Lu et al. (2011) found text messaging dependence and Internet dependence to be uncorrelated with anxiety. According to studies conceptualising problematic technology use as an 'addiction' (Hong et al. 2012; Huang et al. 2013), anxiety can predict mobile phone addiction and Internet addiction (Zboralski et al. 2009; Fu et al. 2010), but these variables can also predict anxiety (Akin and Iskender 2011), suggesting a possible bidirectional relationship.

Although most of the aforementioned studies were conducted among university students, few focused specifically on academic-related anxiety. As academic anxiety might negatively affect students' learning and performance (Slavin 2012), it appears important to ask whether this particular type of anxiety is associated with PSU. Control-value theory (Pekrun 2006) offers a theoretical framework for studies of academic anxiety and indicates that academic anxiety can be associated with learning strategies and self-regulation. It appears likely that PSU - at least to some extent-represents self-regulation failure and that it could have associations with learning strategies. Consequently, the present study investigated the relationship between PSU and academic anxiety among Chinese college students. 


\section{Academic Procrastination and PSU}

Steel (2007) defined procrastination as 'voluntarily delay[ing] an intended course of action despite expecting to be worse off for the delay' (p. 7). In academic situations, procrastination is a widespread phenomenon and it has been found that students often procrastinate when approaching academic tasks (e.g. Klassen et al. 2009; Lay and Silverman 1996). Several studies have focused on the relationship between academic procrastination and Internet use. For example, high levels of Facebook use were found to correlate with higher levels of academic procrastination in a student sample (Sahin 2014). However, in a similar study, no significant associations were found between academic procrastination and problematic Internet use (Odaci 2011). Consequently, evidence regarding this relationship remains unclear, and therefore, it is relevant to examine whether there is an association between academic procrastination and PSU in Chinese college students because smartphones could be seen as a distraction tool that facilitates procrastination. To the present authors' knowledge, no empirical study has focused on the relationship between academic procrastination and PSU. Also, the theoretical model of procrastination proposed by Schraw et al. (2007) did not suggest such an association. Thus, it appears necessary to investigate the relationship between PSU and academic procrastination.

Several studies in educational settings have suggested that procrastination is associated with general or test anxiety (Cassady and Johnson 2002; Fritzsche et al. 2003; Klassen et al. 2009). Schraw et al. (2007)'s theoretical model indicates that one maladaptive aspect of academic procrastination is fear of failure, which is a clear cognitive symptom of anxiety (Zeidner 1998). Therefore, an association between anxiety and procrastination has been both theoretically and empirically supported. Considering the association between anxiety and PSU discussed previously, it appears interesting to ask whether anxiety might mediate any relationship between PSU and academic procrastination.

\section{Self-Regulation and PSU}

Self-regulation has been described as 'those processes, internal and/or transactional, that enable an individual to guide his/her goal-directed activities over time and across changing circumstances (contexts)' (Karoly 1993, p. 25). Billieux et al.'s (2015a) pathway model suggests that impulsivity, which appears to represent the failure of self-regulation, can lead to problematic mobile phone use. Several studies have suggested that low levels of self-regulation predict greater Internet/mobile phone use, as well as negative consequences such as anxiety (LaRose and Eastin 2004; LaRose et al. 2003; Soror et al. 2012). Low self-regulation has been found to negatively predict problematic smartphone use in European samples (Gökçearslan et al. 2016; Van Deursen et al. 2015). However, it remains unclear whether this association exists among mainland Chinese college students.

\section{Life Satisfaction and PSU}

Life satisfaction has been investigated in many studies and is widely acknowledged as one important aspect of subjective wellbeing (Diener et al. 2002). Several empirical studies have explored the relationship between life satisfaction and PSU and obtained different results. For example, no direct significant relationship was found between life satisfaction and mobile 
phone use or texting among a US sample (Lepp et al. 2014). They found that mobile phone use and texting significantly predicted GPA and anxiety, while GPA and anxiety significantly predicted life satisfaction. Similarly, in another study, smartphone addiction was not directly correlated with life satisfaction, while stress and GPA were predicted by smartphone addiction and significantly predicted life satisfaction (Samaha and Hawi 2016). Nevertheless, in different contexts, life satisfaction has been found to be correlated with PSU and also negatively affected by Facebook use in multi-cultural samples (Dayapoglu et al. 2016; Kross et al. 2013). To the present authors' knowledge, no studies have ever investigated the relationship between life satisfaction and PSU among Chinese mainland university students. Therefore, it is timely to investigate whether life satisfaction is reduced by PSU in Chinese college students.

\section{Aims and Hypotheses}

Based upon the aforementioned theoretical and empirical literature, there are several questions that need to be investigated empirically, especially in the context of Chinese universities. Consequently, the present study explored the prevalence of PSU among Chinese university students and its relationship with academic anxiety, academic procrastination, self-regulation and life satisfaction. Six hypotheses are proposed: (i) problematic smartphone use positively will predict academic anxiety, (ii) academic anxiety will positively predict academic procrastination, (iii) problematic smartphone use will positively predict academic procrastination, (iv) problematic smartphone use will positively predict academic procrastination mediated via academic anxiety, (v) self-regulation will negatively predict problematic smartphone use, and (vi) problematic smartphone use will negatively predict life satisfaction. These hypotheses are presented as a hypothesised model in Fig. 1.

\section{Methods}

\section{Participants}

A total of 475 undergraduate students were recruited via convenience sampling at a university in South China. The average age of participants was 19.77 years $(S D=1.11)$, ranging from 16

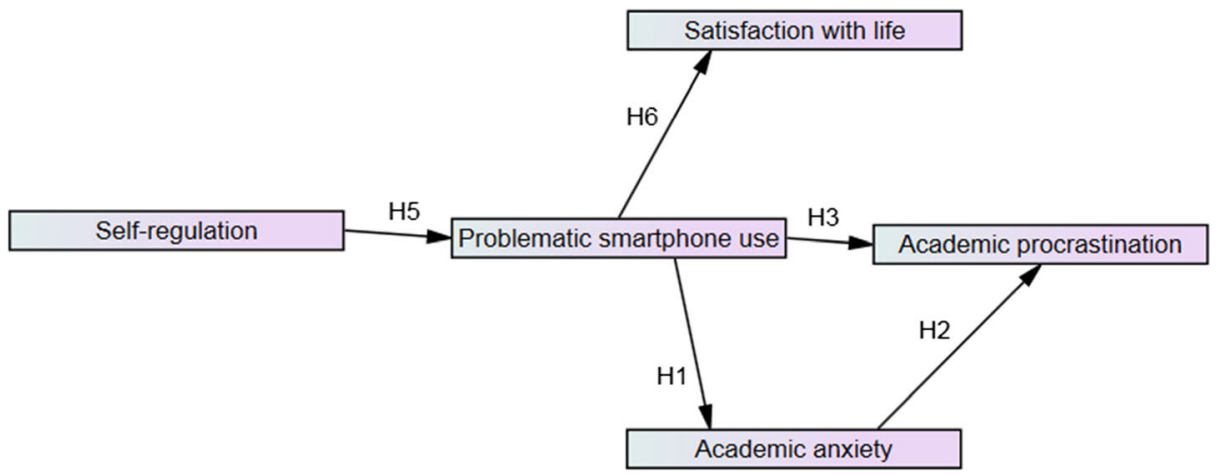

Fig. 1 Model of hypotheses 
to 27 years. There were 266 males and 209 females. The participants were studying a range of subjects including English, administrative management, software engineering, media and mechanics.

\section{Measures}

Smartphone Addiction Scale - Short Version (SAS-SV; Kwon et al. 2013) PSU was assessed using the SAS-SV. The SAS-SV comprises ten items (e.g. 'My smartphone is on my mind even when I am not using it') and is answered using a 6-point Likert scale ranging from 'strongly disagree' (1) to 'strongly agree' (6). Given that the current study was carried out among Chinese students, items related to Twitter and Facebook in the original version were changed into 'WeChat or other social media'. The cut-off points for smartphone addiction were those used by the scale developers (i.e. 33 out of 50 for females and 31 out of 50 for males). Cronbach's alpha was good in the present study $(\alpha=0.80)$.

Academic Emotions Questionnaire (AEQ: Pekrun et al. 2005) Academic anxiety was assessed using modified versions of the anxiety subscales of the AEQ. The modified AEQ-anxiety is a 12-item measure (e.g. 'I feel nervous in class') answered on a 5point Likert scale and rated from 'strongly disagree' (1) to 'strongly agree' (5). It assesses academic anxiety in class, learning and test situations. Cronbach's alpha for the three subscales as a whole was good in the present study $(\alpha=0.82)$.

Irrational Procrastination Scale (IPS: Steel 2010) Academic procrastination was assessed using the modified IPS comprising eight items (e.g. 'My life would be better if I did some activities or tasks earlier') answered on a 5-point Likert scale ranging from 'not at all true of me' (1) to 'very true of me' (5). Cronbach's alpha was 0.60 in the present study. According to Loewenthal (2004), this reliability is acceptable for this scale with fewer than ten items.

Self-Regulation Scale (SRS: Diehl et al. 2006) Self-regulation was assessed using the SRS, a ten-item scale (e.g. 'I stay focused on my goal and don't allow anything to distract me from my plan of action') answered on a 4-point Likert scale ranging from 1 ('Not at all true') to 4 ('Completely true'). Cronbach's alpha was adequate in the present study $(\alpha=0.69)$.

Satisfaction With Life Scale (SWLS; Diener et al. 1985) Life satisfaction was assessed using the SWLS, a five-item scale (e.g. 'If I could live my life over, I would change almost nothing') answered an a Likert scale ranging from 1 (strongly disagree) to 7 (strongly agree). Cronbach's alpha was good in the present study $(\alpha=$ $0.78)$.

All scales except for the SWLS were translated by the researchers into Chinese and validated through a standardised back-translation procedure (Beaton et al. 2000). The validated Chinese version of the SWLS by Bai et al. (2011) was used in the present study. The scales were tested in pilot studies and three of them were modified prior to the main study (full details available on request from the first author). 


\section{Procedure}

Participants were recruited by their English teachers who agreed to distribute the questionnaires during class breaks. The teachers and the first author introduced the present study to the students before distributing the paper-based questionnaires. The participants read the information at the beginning of the survey and completed it after providing informed consent. A pilot study was conducted prior to the main data collection with undergraduate students in the same university (details available on request from the first author).

\section{Data Analysis}

Descriptive statistics for each scale (mean scores, standard deviations, skewness, Cronbach's alpha, etc.) were calculated. Pearson's product-moment correlation coefficient was used to calculate the strength of association between measures. Independent samples $t$ tests were conducted to test gender differences in the five study variables, and effect sizes of mean differences were calculated using Cohen's $d$. Path analysis was adopted using AMOS version 23. Since AMOS requires complete data (Byrne 2010), missing data were replaced using regression imputation.

\section{Ethics}

All participants gave their informed consent for scientific use, and all data were anonymised. The research met the required ethical standards and was approved by the research team's university ethics committee. The study procedures were carried out in accordance with the Declaration of Helsinki. However, it transpired that four participants were under the age of 18 years (i.e. 16 and 17 year olds). This was unexpected in the undergraduate student context, and therefore, parental permission had not been sought.

\section{Results}

\section{Descriptive Statistics}

Descriptive statistics for the total scores of the five scales are shown in Table 1. The observed ranges of the scales were as expected. The skewness and kurtosis values indicate that all scores were normally distributed (see Table 1). The medians of corrected item-total correlations were all above 0.30 , indicating that the items were largely correlated with the scales. The scales were internally consistent as the Cronbach's alpha values were acceptable for the short scales with no more than ten items (Loewenthal 2004). Overall, the data from 475 participants were suitable for further analysis.

\section{Independent Samples $t$ Tests}

Independent samples $t$ tests were conducted to ascertain whether there were gender differences for any of the five variables. Levene's test was applied before reporting the $t$ values. Significant gender differences were found for two variables - problematic smartphone use and self- 
Table 1 Descriptive scale statistics

\begin{tabular}{|c|c|c|c|c|c|c|c|c|c|}
\hline \multirow[t]{2}{*}{ Scale } & \multirow[t]{2}{*}{ No. of items } & \multicolumn{2}{|l|}{ Range } & \multirow[t]{2}{*}{$M$} & \multirow[t]{2}{*}{$S D$} & \multirow[t]{2}{*}{ Skewness } & \multirow[t]{2}{*}{ Kurtosis } & \multirow[t]{2}{*}{$\mathrm{M}^{\mathrm{R}}$} & \multirow[t]{2}{*}{$\alpha$} \\
\hline & & Potential & Observed & & & & & & \\
\hline SAS-SV & 10 & $10-60$ & $10-60$ & 36.70 & 7.55 & 0.05 & 0.31 & 0.49 & 0.80 \\
\hline IPS & 8 & $8-40$ & $11-40$ & 25.14 & 4.74 & -0.02 & 0.32 & 0.38 & 0.66 \\
\hline AEQ-anxiety & 12 & $12-60$ & $12-54$ & 30.48 & 8.07 & 0.00 & -0.13 & 0.48 & 0.82 \\
\hline SRS & 10 & $10-40$ & $13-40$ & 26.16 & 3.71 & 0.06 & 1.12 & 0.37 & 0.69 \\
\hline SWLS & 5 & $5-35$ & $5-35$ & 18.35 & 5.37 & 0.17 & -0.03 & 0.58 & 0.78 \\
\hline
\end{tabular}

$N=475$

$M^{R}$ median of corrected item-total correlations

regulation. Females $(M=37.89, S D=7.06)$ reported statistically significantly higher levels of problematic smartphone use than males $(M=35.77, S D=7.80 ; t(473)=3.07, p<0.01)$, but the effect size of this difference was small $(d=-0.28)$. There was also a significant difference between the self-reported self-regulation of females $(M=25.67, S D=3.84)$ and males $(M=$ 26.55, $S D=3.56), t(473)=-2.58, p<0.05$, with males scoring higher than females, but this effect size was also small $(d=0.24)$. Because the effect sizes were small, it was judged appropriate to combine male and female participants into a single sample for further analysis (Table 2).

\section{Correlation Analyses}

Pearson's product-moment correlation coefficients were calculated, and the five variables were almost all significantly correlated with each other. PSU was significantly and positively correlated with academic procrastination $(r=0.36, p<0.01)$ and academic anxiety $(r=0.28$, $p<0.01)$, and negatively correlated with self-regulation $(r=-0.35, p<0.01)$ and life satisfaction $(r=-0.16, p<0.01)$. Academic procrastination was significantly and positively correlated with academic anxiety $(r=0.39, p<0.01)$, and negatively correlated with self-regulation $(r=$ $-0.39, p<0.01)$ and life satisfaction $(r=-0.16, p<0.01)$. Self-regulation was significantly and negatively correlated with academic anxiety $(r=-0.35, p<0.01)$, and positively correlated with life satisfaction $(r=0.26, p<0.01)$. However, there was no significant correlation between academic anxiety and life satisfaction $(p>0.05)$. Overall, the significant correlations

Table 2 Gender differences for problematic smartphone use, academic procrastination, academic anxiety, selfregulation and satisfaction with life

\begin{tabular}{|c|c|c|c|c|c|c|c|}
\hline & \multicolumn{2}{|c|}{$\begin{array}{l}\text { Female } \\
N=209\end{array}$} & \multicolumn{2}{|c|}{$\begin{array}{l}\text { Male } \\
N=266\end{array}$} & \multirow[b]{2}{*}{$F$} & \multirow[b]{2}{*}{$t(d f)$} & \multirow[b]{2}{*}{$d$} \\
\hline & $M$ & $S D$ & $M$ & $S D$ & & & \\
\hline Problematic smartphone use & 37.89 & 7.06 & 35.77 & 7.80 & 1.13 & $3.07(473)^{* *}$ & -0.28 \\
\hline Academic procrastination & 25.53 & 4.90 & 24.83 & 4.60 & 2.20 & $1.61(473)$ & -0.15 \\
\hline Academic anxiety & 30.08 & 7.60 & 30.80 & 8.42 & 1.71 & $-0.96(473)$ & 0.09 \\
\hline Self-regulation & 25.67 & 3.84 & 26.55 & 3.56 & 0.17 & $-2.58(473)^{*}$ & 0.24 \\
\hline Satisfaction with life & 18.30 & 5.30 & 18.39 & 5.43 & 0.38 & $-0.18(473)$ & 0.02 \\
\hline
\end{tabular}

$* p<0.05 ; * * p<0.01$ 
indicated that the data were suitable for further analysis using structural equation modelling (SEM) (Table 3).

\section{Path Analysis}

SEM is used to analyse complex models with multiple variables. Besides calculating path estimates, it helps to judge whether a model fits the data well (Muijs 2004). In order to test the hypothesised model, one element of SEM (i.e. path analysis) was applied using AMOS. The item parcelling method was adopted while the total scores for the five scales were included in the model as observed variables. The criteria for a good fit are as follows: $\chi^{2} / d f<3, R M S E A<$ $0.08, C F I>0.90$ (Bakker et al. 2007), or RMSEA <0.06, CFI $>0.95$ (Hu and Bentler 1999). As shown in Fig. 2, the initial model, which was in line with the hypothesised model, did not fit the data well $\left(\chi^{2}=93.24, d f=5, \chi^{2} / d f=18.65, p<0.001, C F I=0.72, R M S E A=0.193\right)$. However, according to the modification indices provided by AMOS version 23, additional covariance between self-regulation and errors 1,3 and 4 were recommended. As selfregulation was significantly correlated with life satisfaction, academic anxiety and academic procrastination, three paths were added into the model from self-regulation to the three variables, connected to errors 1, 3 and 4 . Figure 3 shows that this modified model had a good fit $\left(\chi^{2}=2.05, d f=2, \chi^{2} / d f=1.03, p=0.36, C F I=1.00, R M S E A=0.008\right.$. As shown in Table 4, there were significant fit changes from the initial model to the modified model.

The standard regression weights of the paths in the modified model are shown in Fig. 3. Significance was tested using bootstrapping (10,000 times) in AMOS. The model shows that PSU was negatively predicted by self-regulation $(\beta=-0.35, p<0.001)$. Furthermore, PSU positively predicted academic anxiety $(\beta=0.18, p<0.001)$ and academic procrastination $(\beta=$ $0.21, p<0.001)$. Academic anxiety positively predicted academic procrastination $(\beta=0.25$, $p<0.001)$. Self-regulation positively predicted life satisfaction $(\beta=0.23, p<0.001)$, and negatively predicted academic anxiety $(\beta=-0.29, p<0.001)$ and academic procrastination $(\beta=-0.23, p<0.001)$. PSU was not a significant predictor of life satisfaction in the final model.

Table 5 shows the mediating relationships identified in the final, and best-fitting, model. The significance of the indirect effects was tested using bootstrapping (10,000 times) in AMOS. PSU had significant direct effects on academic procrastination $(\beta=0.36, p<0.001)$ and academic anxiety $(\beta=0.27, p<0.001)$ respectively. Academic procrastination was significantly predicted by PSU $(\beta=0.28, p<0.001)$ and academic anxiety $(\beta=0.31, p<0.001)$ when academic anxiety was added into the relationship between PSU and academic procrastination. The effect of PSU on academic procrastination decreased from 0.36 to 0.28 when academic anxiety was added in as a mediating variable, and the indirect effect was significant

Table 3 Pearson product-moment correlations

\begin{tabular}{|c|c|c|c|c|c|}
\hline & 1 & 2 & 3 & 4 & 5 \\
\hline 1. Problematic smartphone use & - & & & & \\
\hline 2. Academic procrastination & $0.36^{* *}$ & - & & & \\
\hline 3. Academic anxiety & $0.28 * *$ & $0.39 * *$ & - & & \\
\hline 4. Self-regulation & $-0.35 * *$ & $-0.39 * *$ & $-0.35 * *$ & - & \\
\hline 5. Satisfaction with life & $-0.16 * *$ & $-0.16^{* *}$ & -0.08 & $0.26 * *$ & - \\
\hline
\end{tabular}

$* * p<0.01$ (two-tailed) 


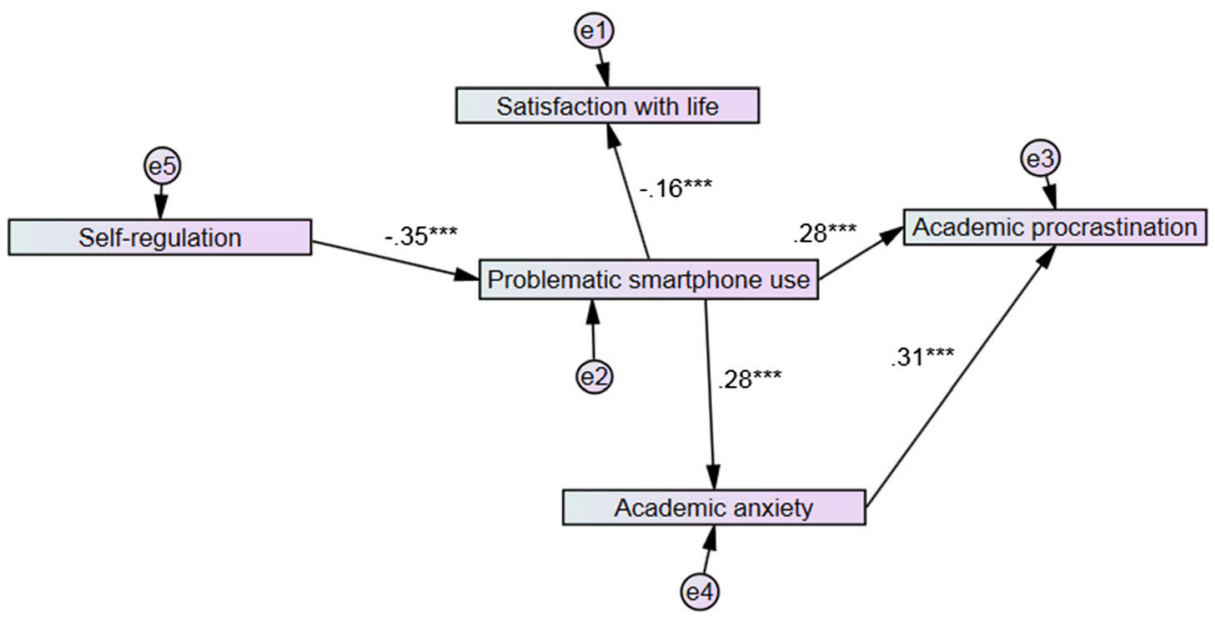

Fig. 2 Initial model. $\chi^{2}=93.24, d f=5, \chi^{2} / d f=18.65, p<0.001, \mathrm{CFI}=0.72$, RMSEA $=0.193$. $* * * p<0.001$

$(p<0.001)$. Therefore, academic anxiety partially mediated the relationship between PSU and academic procrastination. The other mediating relationships in Table 5 were tested and approved in the same way as above, and the indirect effects were all significant. The effects of self-regulation on anxiety and procrastination were partially mediated by PSU. Anxiety was a partial mediator between self-regulation and procrastination.

\section{Discussion}

\section{Summary of the Results}

The present study investigated problematic smartphone use (PSU) and its potential correlates in a sample of Chinese university students. The results of the study confirmed a modified

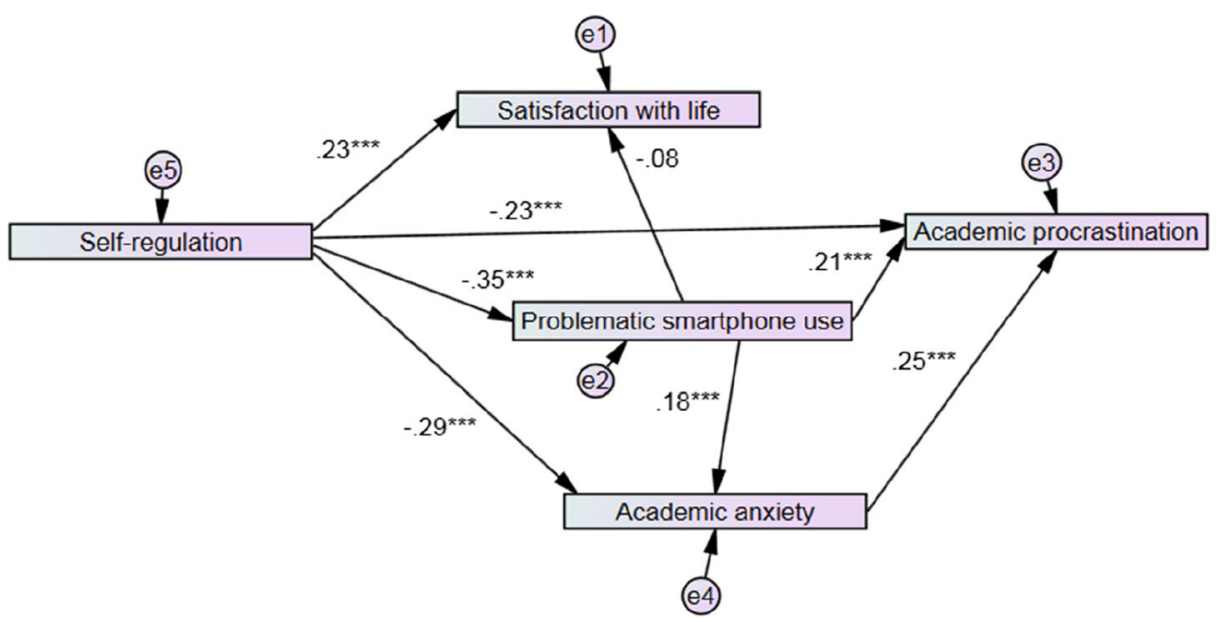

Fig. 3 Modified model. $\chi^{2}=2.05, d f=2, \chi^{2} / d f=1.03, p=0.36, \mathrm{CFI}=1.00, \mathrm{RMSEA}=0.008$. $* * * p<0.001$ 
Table 4 Summary of the model fit indices

\begin{tabular}{|c|c|c|c|c|c|c|c|c|c|}
\hline & \multirow[b]{2}{*}{$\chi^{2}$} & \multirow[b]{2}{*}{$d f$} & \multirow[b]{2}{*}{$\chi^{2} / d f$} & \multirow[b]{2}{*}{$p$} & \multirow[b]{2}{*}{$C F I$} & \multirow[b]{2}{*}{ RMSEA } & \multicolumn{3}{|c|}{ Fit changes } \\
\hline & & & & & & & $\Delta \chi^{2}$ & $\Delta \chi^{2} / d f$ & $\triangle C F I$ \\
\hline Initial model & 93.24 & 5 & 18.65 & 0.00 & 0.72 & 0.193 & & & \\
\hline Modified model & 2.05 & 2 & 1.03 & 0.36 & 1.00 & 0.008 & 91.19 & 17.62 & 0.88 \\
\hline
\end{tabular}

model based on the hypothesised model. Study variables were significantly correlated with each other except for life satisfaction and academic anxiety. Hypotheses 1 to 5 were supported in the modified model. In particular, PSU was significantly and negatively predicted by selfregulation. PSU also significantly and positively predicted academic anxiety and academic procrastination. These findings indicate that improving self-regulation may be one way of addressing PSU and related problems, at least in the context of the Chinese university undergraduates in the present study.

Furthermore, besides the paths in the hypothesised model, self-regulation positively predicted life satisfaction (subjective wellbeing) and negatively predicted academic anxiety and academic procrastination. Hypothesis 6 was not supported because PSU was not a significant predictor of life satisfaction. Several mediation relationships were identified. PSU mediated the relationships between self-regulation and both academic anxiety and academic procrastination. Overall, the present study found that PSU had negative associations with Chinese university students' academic behaviours such as anxiety and procrastination, while self-regulation was also a key variable when considering PSU and its effects. However, it is important to note that these data are correlational and cannot conclusively demonstrate the direction of effects.

\section{Comparison with Previous Studies and Implications}

Table 6 illustrates the comparison between the present study and key previously published studies. The grand mean of the IPS was calculated in order to compare it with the original grand mean in Steel's (2010) study. The AEQ-anxiety subscale scores were multiplied by 35/ 12 because the measure was shortened from 35 to 12 items in the present study. Consequently, it can be seen that PSU was reported more frequently in the present study than in others with different samples. Participants in the present study scored much higher than those in Kwon et al.'s (2013) study of 540 Korean students, with a very large effect size $(d=-1.22)$. As

Table 5 Mediation analysis

\begin{tabular}{llll}
\hline & Without mediator & With mediator & \\
\cline { 3 - 3 } & Direct effect & Direct effect & Indirect effect \\
\hline $\mathrm{PSU} \rightarrow \mathrm{AA} \rightarrow \mathrm{AP}$ & $0.36^{* * *}$ & $0.28^{* * *}$ & $0.09 * * *$ \\
$\mathrm{SR} \rightarrow \mathrm{PSU} \rightarrow \mathrm{AA}$ & $-0.35^{* * *}$ & $-0.29 * * *$ & $-0.06^{* * *}$ \\
$\mathrm{SR} \rightarrow \mathrm{PSU} \rightarrow \mathrm{AP}$ & $-0.39^{* * *}$ & $-0.30^{* * *}$ & $-0.09^{* * *}$ \\
$\mathrm{SR} \rightarrow \mathrm{AA} \rightarrow \mathrm{AP}$ & $-0.39^{* * *}$ & $-0.29 * * *$ & $-0.10^{* * *}$ \\
\hline
\end{tabular}

The results indicate partial mediation in all paths

$P S U$ problematic smartphone use, $A A$ academic anxiety, $A P$ academic procrastination, $S R$ self-regulation

$* * * p<0.001$ 


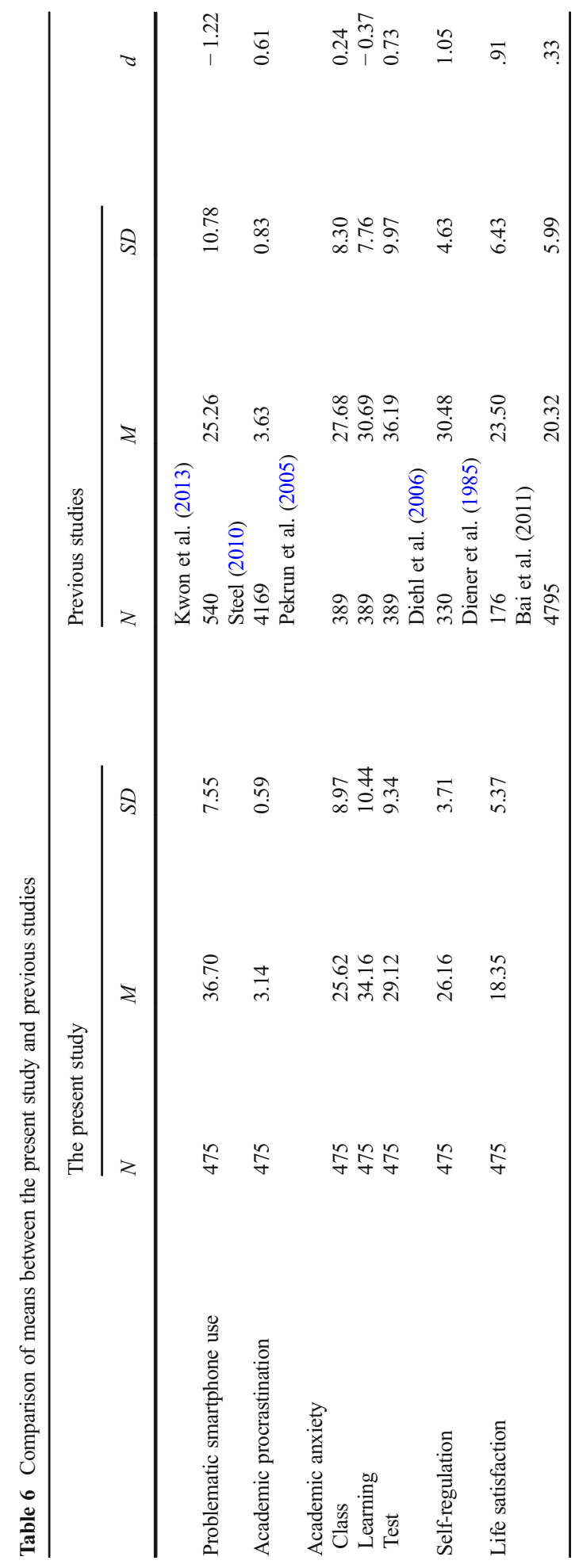


shown in Table 7, participants in the present study also reported higher levels of addictive smartphone use than a sample of Korean teenagers (Kee et al. 2016) and the multi-national sample in (Chotpitayasunondh and Douglas 2016) because more participants scored over the suggested cut-off points for addiction on the SAS-SV (33 out of 50 for females and 31 out of 50 for males). In the present study, 151 out of 209 females (72.25\%) scored over 33 points and 193 of 266 males $(72.56 \%)$ scored over 31 points. Evidently, the Chinese undergraduate participants reported very high levels of smartphone use, notably higher than young people in other countries.

This finding raises important questions about why young Chinese people report higher levels of smartphone use, and whether this really is problematic. Griffiths et al. (2016) have argued there are cultural differences in attitudes towards technology use in South East Asia. Based on their own visits to treatment clinics for technology-based addictions in South East Asia, they noted that any activity disrupts and/or impedes education and/or family dynamics appears to be pathologised by parents. When completing scales relating to internet and/or smartphone use, it is likely that some items are endorsed (e.g. having lied to individuals about their technology use, having arguments with the family about technology use) not because they are using such technologies excessively and/or problematically but because they are using the technologies for non-educational purposes. This helps explain the highly inflated prevalence rates of technology-based 'addictions' in countries such as China. In short — and from a cultural perspective - any smartphone use (not just excessive use) appears to cause problems for the user on an individual level because the use is often pathologised by parents.

In the present study, participants reported lower levels of procrastination than the multinational study of Steel (2010) with a moderate effect size $(d=0.61)$. Compared to the Canadian undergraduates in Pekrun et al.'s (2005) study, participants in the present study appeared to be a little more anxious about learning $(d=-0.37)$ but less anxious about classes $(d=0.24)$ and tests $(d=0.73)$. Participants in the present study also reported lower levels of self-regulation than the American study by Diehl et al. (2006) with a large effect size ( $d=$ 1.05), which is interesting in light of the higher levels of PSU also reported by participants in the present study. Participants in the present study also appeared to be less satisfied with their lives than the American sample in Diener et al.'s (1985) study with a large effect size ( $d=$ 0.91). Interestingly, they also reported slightly lower life satisfaction than the large Chinese mainland sample reported more than 30 years ago by Diener et al. (1985) but with a small effect size $(d=0.33)$.

It appears that cultural differences are likely to have some impact on the differences observed between different study samples. Chinese mainland undergraduates in the present study perceived themselves as heavy smartphone users but tended to be more confident about their self-regulation. One possibility is that Chinese college students find it hard to control themselves on smartphone use because college represents a period of freedom after many years

Table 7 Comparison of the percentage of 'addictive' smartphone users between studies

\begin{tabular}{|c|c|c|c|c|c|c|}
\hline \multirow[t]{2}{*}{ Gender } & \multicolumn{2}{|c|}{ The present study } & \multicolumn{2}{|c|}{ Chotpitayasunondh and Douglas's (2016) study } & \multicolumn{2}{|c|}{ Kee et al.'s (2016) study } \\
\hline & $n / N$ & Percentage & $n / N$ & Percentage & $n / N$ & Percentage \\
\hline Female & $151 / 209$ & $72.25 \%$ & $51 / 158$ & $32.3 \%$ & $38 / 72$ & $52 \%$ \\
\hline Male & $193 / 266$ & $72.56 \%$ & $27 / 93$ & $29 \%$ & $12 / 28$ & $42 \%$ \\
\hline
\end{tabular}

$n$ number of participants scored above the cut-off value, $N$ total number 
of pressure and rigorous management in school. It is possible that the level of control and restriction during the school years is higher in China than in other places. It is also possible that, because of their previous experience of strict school management, participants reported higher levels of self-regulation and lower levels of procrastination based on their behaviour at school, which may have become habitual with regard to academic work. Meanwhile, the environmental effects of the university in the present study cannot be ignored. The reported high levels of smartphone use might indicate a poor academic context (participants also reported higher levels of learning anxiety than other samples), or insufficient training in personal efficiency or effectiveness in the university.

However, such differences, while interesting and worthy of further empirical research, do not affect the hypotheses tested in the present study which only examined Chinese students. The modified model based on the hypothesised model was acceptable and fitted the data well. Hypotheses 1 to 5 were supported in the modified model. Previous studies have found correlational and/or predictive relationships with anxiety and the frequency of mobile phone use, dependence on mobile phone use, and addiction to mobile phone use (Akin and Iskender 2011; Ha et al. 2008; Hong et al. 2012, etc.). The present study provides support for this relationship because PSU significantly predicted academic anxiety in the model. Interestingly, frequent use of mobile phones has been found to predict higher anxiety (Lepp et al. 2014), while anxiety has also been found to predict mobile phone addiction (Hong et al. 2012; Huang et al. 2013). It appears that there may be a bidirectional relationship between anxiety and PSU. However, it is clear that the context of the studies and the types of anxiety need to be considered when interpreting findings. The present study indicated that the Chinese mainland undergraduate students may be likely to suffer academic anxiety when they cannot control their smartphone use. It appears that to overcome PSU, more training or guidance may be useful in (i) successfully regulating smartphone use, (ii) how to benefit from smartphones, and (iii) providing skills to overcome mental health issues such as academic anxiety.

Although no studies have ever investigated the relationship between PSU and academic procrastination, Internet use has been found to be associated with procrastination (Odaci 2011; Sahin 2014). The present study found that PSU predicted academic procrastination, and that the association was partially mediated by academic anxiety. It appears that the students in the present study were more likely to procrastinate when they could not or did not control their smartphone use, or when they felt anxious (possibly associated to their PSU). Again, they may benefit from training on time-management skills or personal effectiveness, especially for procrastination associated with smartphone use.

In previous studies, self-regulation has been found to be a negative predictor of PSU in European samples (Gökçearslan et al. 2016; Van Deursen et al. 2015). Low self-regulation has also been found to predict greater mobile phone and Internet use, and anxiety (LaRose and Eastin 2004; LaRose et al. 2003; Soror et al. 2012). In line with previous studies, the present study found that PSU was negatively predicted by self-regulation. Furthermore, the present study found that self-regulation predicted academic anxiety, procrastination and life satisfaction. It is noteworthy that PSU partially mediated the relationships from self-regulation to academic anxiety and procrastination. Consequently, PSU appears to be a key factor which should be considered when discussing the negative consequences of poor self-regulation.

Hypothesis 6 was rejected in the present study because PSU did not predict satisfaction with life significantly in the modified model although the path was significant in the initial model. Previous studies have found direct or indirect relationships between PSU and life satisfaction. The present study found they were significantly correlated but the path model was 
not significant. Therefore, further investigation of this relationship in different contexts is needed as well as examining whether the non-significant pathway is specific to the present sample.

Overall, the present study suggests that higher self-reported PSU predicted high levels of academic anxiety and academic procrastination. Self-regulation was a predictor of PSU. It appears that destructive academic emotions and behaviours among Chinese university students, such as anxiety and procrastination, might partly be a consequence of poor self-control concerning their smartphone use. Although the relationships cannot be said to be causal (because no experimental interventions were used in the present study), the results indicate that the training of youth in resilience skills to control their use of smartphones might be one approach to reducing anxiety and procrastination among the undergraduates in this context. It is clear that anxiety and procrastination are not simply predicted by one single factor and are likely to be aetiologically complex. However, the present findings suggest that one possible strategy for reducing levels of academic anxiety, or overcoming academic procrastination, might be to offer training or awareness raising about general self-regulation skills and approaches to smartphone use. However, such interventions would require rigorous development and evaluation. While PSU was significantly correlated with life satisfaction (but with a small effect size), this relationship was not significant in the path model. It remains unclear whether PSU predicts better or worse subjective wellbeing.

\section{Limitations}

There are several limitations of the present study. The present study used self-reported scales to investigate the five variables. It is therefore possible that participants gave socially desirable answers to the questionnaires. This appears unlikely to have been a major problem given the high levels of PSU reported and the good variability observed for each measure. It is also unknown whether the undergraduates completely understood the statements in the survey. If they misunderstood the items, the responses might be biased which could have affected the results. It is possible that this could be a factor in the reduced reliability of two of the present study measures (IPS and SRS). Loewenthal (2004) noted that the Cronbach's alpha value can be affected by the number of items and argued that scales with values above 0.6 can be acceptable when they have fewer than ten items. As the IPS and SRS used in study were made up of eight and ten items, their alpha values were acceptable for data analysis in the present study. These are particular problems for questionnaire designs. However, there are also doubts about whether experimental approaches could be successfully, rigorously and ethically applied to PSU studies, particularly if they involve gaining access to participants' smartphones or limiting their usage.

\section{Future Research and Conclusions}

It appears important for future studies to explore new research methods for investigating PSU rigorously and ethically. Smartphone applications (i.e. 'apps') designed for time management (e.g. QualityTime) can be used in future studies. However, participants might change their behaviours on smartphones when they know their behaviour is being recorded via an app. Furthermore, the SAS-SV investigated few aspects of problematic smartphone use. Several empirical studies have investigated single, specific functions of smartphone use (e.g. Facebook use). It would also be useful to investigate individual aspects of PSU, together with the other 
variables in the present study, rather than focusing solely on more general smartphone use. It is obvious that the undergraduate participants in the present study reported relatively high levels of PSU, much higher than in other samples, contexts and countries. Understanding the aetiology and effects of such high smartphone use among Chinese undergraduates therefore appears important. In-depth qualitative studies could be particularly useful in shedding greater insight in extending the findings presented here. It should also be noted that the present study only investigated undergraduates in one Chinese mainland university, and the findings cannot be generalised to all Chinese students. It is possible, for example, that students at different ages and different stages of their education may respond differently. It is therefore important for future studies to replicate these findings among other groups of Chinese students (e.g. Chinese high school students, Chinese postgraduate students, Chinese students in high and low ranking universities). It would also be empirically valuable to explore these issues in a cross-cultural context.

Funding Sources There is no funding for this study.

Authors' Contribution Zeyang Yang and Kathryn Asbury designed the study. Zeyang Yang conducted data collection and analysis. Zeyang Yang carried out the main bulk of the manuscript writing and literature review. Kathryn Asbury participated in checking methods and results and supporting Zeyang Yang during the data collection and analysis. Kathryn Asbury and Mark D. Griffiths acted in an editorial role when it came to the writing up of the research study. All authors read and approved the final manuscript.

\section{Compliance with ethical standards}

Conflict of Interest The authors declare that they have no conflict of interest.

Ethics This study has been approved by the Ethics Committee of the Department of Education at the University of York. All participants gave their informed consent for scientific use, and all data were anonymised. The research met the required ethical standards and was approved by the research team's university ethics committee. The study procedures were carried out in accordance with the Declaration of Helsinki. However, it transpired that four participants were under the age of 18 years (i.e. 16 and 17 year olds). This was unexpected in the undergraduate student context, and therefore, parental permission had not been sought.

Open Access This article is distributed under the terms of the Creative Commons Attribution 4.0 International License (http://creativecommons.org/licenses/by/4.0/), which permits unrestricted use, distribution, and reproduction in any medium, provided you give appropriate credit to the original author(s) and the source, provide a link to the Creative Commons license, and indicate if changes were made.

\section{References}

Akin, A., \& Iskender, M. (2011). Internet addiction and depression, anxiety and stress. International Online Journal of Educational Sciences, 3(1), 138-148.

American Psychiatric Association. (2013). Diagnostic and statistical manual of mental disorders. Arlington: American Psychiatric Association.

Bai, X., Wu, C., Zheng, R., \& Ren, X. (2011). The psychometric evaluation of the Satisfaction with Life Scale using a nationally representative sample of China. Journal of Happiness Studies, 12(2), 183-197.

Bakker, A. B., Hakanen, J. J., Demerouti, E., \& Xanthopoulou, D. (2007). Job resources boost work engagement, particularly when job demands are high. Journal of Educational Psychology, 99(2), 274-284. 
Beaton, D. E., Bombardier, C., Guillemin, F., \& Ferraz, M. B. (2000). Guidelines for the process of cross-cultural adaptation of self-report measures. Spine, 25(24), 3186-3191.

Bian, M., \& Leung, L. (2015). Linking loneliness, shyness, smartphone addiction symptoms, and patterns of smartphone use to social capital. Social Science Computer Review, 33(1), 61-79.

Bianchi, A., \& Phillips, J. G. (2005). Psychological predictors of problem mobile phone use. Cyberpsychology \& Behavior, 8(1), 39-51.

Billieux, J. (2012). Problematic use of the mobile phone: A literature review and a pathways model. Current Psychiatry Reviews, 8(4), 299-307.

Billieux, J., Maurage, P., Lopez-Fernandez, O., Kuss, D. J., \& Griffiths, M. D. (2015a). Can disordered mobile phone use be considered a behavioral addiction? An update on current evidence and a comprehensive model for future research. Current Addiction Reports, 2(2), 156-162.

Billieux, J., Philippot, P., Schmid, C., Maurage, P., De Mol, J., \& Van der Linden, M. (2015b). Is dysfunctional use of the mobile phone a behavioural addiction? Confronting symptom-based versus process-based approaches. Clinical Psychology \& Psychotherapy, 22(5), 460-468.

Byrne, B. M. (2010). Structural equation modelling with AMOS: Basic concepts, applications, and programming. New York: Routledge.

Carbonell, X., Chamarro, A., Beranuy, M., Griffiths, M. D., Oberst, U., Cladellas, R., \& Talarn, A. (2012). Problematic internet and cell phone use in Spanish teenagers and young students. Anales de Psicologia, 28, 789-796.

Cassady, J. C., \& Johnson, R. E. (2002). Cognitive test anxiety and academic performance. Contemporary Educational Psychology, 27(2), 270-295.

Chotpitayasunondh, V., \& Douglas, K. M. (2016). How "phubbing" becomes the norm: The antecedents and consequences of snubbing via smartphone. Computers in Human Behavior, 63, 9-18.

Davis, R. A. (2001). A cognitive-behavioral model of pathological internet use. Computers in Human Behavior, 17(2), 187-195.

Dayapoglu, N., Kavurmaci, M., \& Karaman, S. (2016). The relationship between the problematic mobile phone use and life satisfaction, loneliness, and academic performance in nursing students. International Journal of Caring Sciences, 9(2), 647-652.

Diehl, M., Semegon, A. B., \& Schwarzer, R. (2006). Assessing attention control in goal pursuit: A component of dispositional self-regulation. Journal of Personality Assessment, 86(3), 306-317.

Diener, E. D., Emmons, R. A., Larsen, R. J., \& Griffin, S. (1985). The satisfaction with life scale. Journal of Personality Assessment, 49(1), 71-75.

Diener, E., Lucas, R. E., \& Oishi, S. (2002). Subjective well-being: The science of happiness and life satisfaction. In C. R. Snyder \& S. J. Lopez (Eds.), The handbook of positive psychology (pp. 63-73). Oxford: Oxford University Press.

Fritzsche, B. A., Young, B. R., \& Hickson, K. C. (2003). Individual differences in academic procrastination tendency and writing success. Personality and Individual Differences, 35(7), 1549-1557.

Fu, K. W., Chan, W. S., Wong, P. W., \& Yip, P. S. (2010). Internet addiction: Prevalence, discriminant validity and correlates among adolescents in Hong Kong. British Journal of Psychiatry, 196(6), 486-492.

Gökçearslan, Ș., Mumcu, F. K., Haşlaman, T., \& Çevik, Y. D. (2016). Modelling smartphone addiction: The role of smartphone usage, self-regulation, general self-efficacy and cyberloafing in university students. Computers in Human Behavior, 63, 639-649.

Griffiths, M. D. (1995). Technological addictions. Clinical Psychology Forum, 76, 14-19.

Griffiths, M. D. (2000). Internet addiction-Time to be taken seriously? Addiction Research, 8, 413-418.

Griffiths, M. D. (2005). A 'components' model of addiction within a biopsychosocial framework. Journal of Substance Use, 10, 191-197.

Griffiths, M. D. (2017). Behavioural addiction and substance addiction should be defined by their similarities not their dissimilarities. Addiction, 112, 1718-1720.

Griffiths, M. D., Kuss, D. J., Billieux, J., \& Pontes, H. M. (2016). The evolution of internet addiction: A global perspective. Addictive Behaviors, 53, 193-195.

Ha, J. H., Chin, B., Park, D.-H., Ryu, S.-H., \& Yu, J. (2008). Characteristics of excessive cellular phone use in Korean adolescents. Cyberpsychology \& Behavior, 11(6), 783-784.

Hong, F.-Y., Chiu, S.-I., \& Huang, D.-H. (2012). A model of the relationship between psychological characteristics, mobile phone addiction and use of mobile phones by Taiwanese university female students. Computers in Human Behavior, 28(6), 2152-2159.

Hu, L., \& Bentler, P. M. (1999). Cutoff criteria for fit indexes in covariance structure analysis: Conventional criteria versus new alternatives. Structural Equation Modeling, 6(1), 1-55.

Huang, H., Zhou, C., \& Yu, L. (2013). Association between mobile phone addiction and mental health among college students. Chinese Journal of School Health, 34(9), 1074-1076. 
Hussain, Z., Griffiths, M. D., \& Sheffield, D. (2017). An investigation in to problematic smartphone use: The role of narcissism, anxiety, and personality factors. Journal of Behavioral Addictions, 6, 378-386.

Jenaro, C., Flores, N., Gómez-Vela, M., González-Gil, F., \& Caballo, C. (2007). Problematic internet and cellphone use: Psychological, behavioral, and health correlates. Addiction Research \& Theory, 15(3), 309-320.

Karoly, P. (1993). Mechanisms of self-regulation: A systems view. Annual Review of Psychology, 44(1), $23-52$.

Kee, I. K., Byun, J. S., Jung, J. K., \& Choi, J. K. (2016). The presence of altered craniocervical posture and mobility in smartphone-addicted teenagers with temporomandibular disorders. Journal of Physical Therapy Science, 28(2), 339-346.

Klassen, R. M., Ang, R. P., Chong, W. H., Krawchuk, L. L., Huan, V. S., Wong, I. Y., \& Yeo, L. S. (2009). A cross-cultural study of adolescent procrastination. Journal of Research on Adolescence, 19(4), 799-811.

Kross, E., Verduyn, P., Demiralp, E., Park, J., Lee, D. S., Lin, N., Shablack, H., Jonides, J., \& Ybarra, O. (2013). Facebook use predicts declines in subjective well-being in young adults. PLoS One, 8(8), e69841.

Kuss, D. J., Griffiths, M. D., Karila, L., \& Billieux, J. (2014). Internet addiction: A systematic review of epidemiological research for the last decade. Current Pharmaceutical Design, 20, 4026-4052.

Kwon, M., Kim, D. J., Cho, H., \& Yang, S. (2013). The smartphone addiction scale: Development and validation of a short version for adolescents. PLoS One, 8(12), e83558.

LaRose, R., \& Eastin, M. S. (2004). A social cognitive theory of Internet uses and gratifications: Toward a new model of media attendance. Journal of Broadcasting \& Electronic Media, 48(3), 358-377.

LaRose, R., Lin, C. A., \& Eastin, M. S. (2003). Unregulated Internet usage: Addiction, habit, or deficient selfregulation? Media Psychology, 5(3), 225-253.

Lay, C., \& Silverman, S. (1996). Trait procrastination, anxiety, and dilatory behavior. Personality and Individual Differences, 21(1), 61-67.

Lepp, A., Barkley, J. E., \& Karpinski, A. C. (2014). The relationship between cell phone use, academic performance, anxiety, and satisfaction with life in college students. Computers in Human Behavior, 31(1), 343-350.

Leung, L. (2008). Linking psychological attributes to addiction and improper use of the mobile phone among adolescents in Hong Kong. Journal of Children and Media, 2(2), 93-113.

Liu, C. Y., \& Kuo, F. Y. (2007). A study of Internet addiction through the lens of the interpersonal theory. Cyberpsychology \& Behavior, 10(6), 799-804.

Loewenthal, K. M. (2004). An introduction to psychological tests and scales (2nd ed.). Hove: Psychology Press.

Long, J., Liu, T. Q., Liao, Y. H., Qi, C., He, H. Y., Chen, S. B., \& Billieux, J. (2016). Prevalence and correlates of problematic smartphone use in a large random sample of Chinese undergraduates. BMC Psychiatry, 16, 408.

Lopez-Fernandez, O., Kuss, D. J., Romo, L., Morvan, Y., Kern, L., Graziani, P., Rousseau, A., Rumpf, H. J., Bischof, A., Gässler, A. K., Schimmenti, A., Passanisi, A., Männikkö, N., Kääriänen, M., Demetrovics, Z., Király, O., Chóliz, M., Zacarés, J. J., Serra, E., Griffiths, M. D., Pontes, H. M., Lelonek-Kuleta, B., Chwaszcz, J., Zullino, D., Rochat, L., Achab, S., \& Billieux, J. (2017). Self-reported dependence on mobile phones in young adults: A European cross-cultural empirical survey. Journal of Behavioral Addictions, 6 , 168-177.

Lu, X., Watanabe, J., Liu, Q., Uji, M., Shono, M., \& Kitamura, T. (2011). Internet and mobile phone textmessaging dependency: Factor structure and correlation with dysphoric mood among Japanese adults. Computers in Human Behavior, 27(5), 1702-1709.

Ministry of Industry and Information Technology of the People's Republic of China. (2018). The report of communication industry in 2017. Retrieved March 29, 2018, from: http://www.miit.gov.cn/n1146290 /n1146402/n1146455/c6048084/content.html.

Muijs, D. (2004). Doing quantitative research in education with SPSS. London: SAGE.

Odaci, H. (2011). Academic self-efficacy and academic procrastination as predictors of problematic internet use in university students. Computers \& Education, 57(1), 1109-1113.

Pekrun, R. (2006). The control-value theory of achievement emotions: Assumptions, corollaries, and implications for educational research and practice. Educational Psychology Review, 18(4), 315-341.

Pekrun, R., Goetz, T., \& Perry, R. P. (2005). Achievement Emotions Questionnaire (AEQ). User's manual. Munich: Department of Psychology, University of Munich.

Poushter, J. (2016). Smartphone ownership and internet usage continues to climb in emerging economies-But advanced economies still have higher rates of technology use. Retrieved March 29, 2018, from: http:/www. pewglobal.org/2016/02/22/smartphone-ownership-and-internet-usage-continues-to-climb-in-emergingeconomies/.

Sahin, Y. L. (2014). Comparison of users' adoption and use cases of Facebook and their academic procrastination. Digital. Education Review, 25, 127-138.

Samaha, M., \& Hawi, N. S. (2016). Relationships among smartphone addiction, stress, academic performance, and satisfaction with life. Computers in Human Behavior, 57, 321-325. 
Schraw, G., Wadkins, T., \& Olafson, L. (2007). Doing the things we do: A grounded theory of academic procrastination. Journal of Educational Psychology, 99(1), 12-25.

Slavin, R. E. (2012). Educational psychology: Theory and practice. Boston: Pearson.

Soror, A. A., Steelman, Z. R., \& Limayem, M. (2012). Discipline yourself before life disciplines you: Deficient self-regulation and mobile phone unregulated use. In: System Science (HICSS), 2012 45th Hawaii International Conference on (pp. 849-858). New Jersey: IEEE.

Spielberger, C. D. (1972). The nature and measurement of anxiety. In C. D. Spielberger (Ed.), Anxiety: Current trends in theory and research (pp. 23-49). New York: Academic Press.

Statista (n.d.). Number of mobile phone users worldwide from 2013 to 2019 (in billions). Retrieved March 29, 2018, from: https:/www.statista.com/statistics/274774/forecast-of-mobile-phone-users-worldwide/.

Steel, P. (2007). The nature of procrastination. Psychological Bulletin, 133(1), 65-94.

Steel, P. (2010). Arousal, avoidant and decisional procrastinators: Do they exist? Personality and Individual Differences, 48(8), 926-934.

Van Deursen, A. J., Bolle, C. L., Hegner, S. M., \& Kommers, P. A. (2015). Modeling habitual and addictive smartphone behavior: The role of smartphone usage types, emotional intelligence, social stress, selfregulation, age, and gender. Computers in Human Behavior, 45, 411-420.

Wang, H., Huang, H., \& Wu, H. M. (2014). Relationship between personality and mobile phone addiction: A mediating role of social anxiety. Chinese Journal of Clinical Psychology, 3, 447-450.

Widyanto, L., \& Griffiths, M. (2006). Internet addiction: Does it really exist? In J. Gackenbach (Ed.), Psychology and the Internet: intrapersonal, interpersonal, and transpersonal applications (pp. 141-163). Burlington: Academic Press.

Yang, H., \& Lay, Y. (2011). Factors affecting college student's mobile phone dependence and anxiety. Proceedings of the World Congress on Engineering and Computer Science 2011, II, 19-22. Hong Kong: International Association of Engineers.

Yen, C. F., Tang, T. C., Yen, J. Y., Lin, H. C., Huang, C. F., Liu, S. C., \& Ko, C. H. (2009). Symptoms of problematic cellular phone use, functional impairment and its association with depression among adolescents in southern Taiwan. Journal of Adolescence, 32(4), 863-873.

Young, K. S. (1998a). Caught in the Net: How to recognize the signs of Internet addiction and a winning strategy for recovery. New York: Wiley.

Young, K. S. (1998b). Internet addiction: The emergence of a new clinical disorder. Cyberpsychology \& Behavior, 1(3), 237-244.

Zboralski, K., Orzechowska, A., Talarowska, M., Darmosz, A., Janiak, A., Janiak, M., Florkowski, A., \& Gałecki, P. (2009). The prevalence of computer and internet addiction among pupils. Post py Higieny $i$ Medycyny Doświadczalnej, 63, 8-12.

Zeidner, M. (1998). Test anxiety: The state of the art. New York: Plenum. 